Article

\title{
Highly Active Hydrogenation Catalysts Based on Pd Nanoparticles Dispersed along Hierarchical Porous Silica Covered with Polydopamine as Interfacial Glue
}

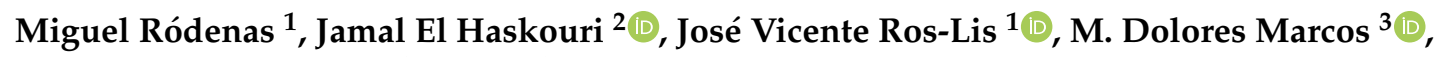 \\ Pedro Amorós $2, *\left(\mathbb{D}\right.$, M. Ángeles Úbeda $1, * \mathbb{D}$ and Francisco Pérez-Pla ${ }^{2, *(D)}$ \\ 1 Departamento de Química Inorgànica, Universitat de València, Dr. Moliner 50, Burjassot, 46100 València, \\ Spain; rodenasespada@gmail.com (M.R.); j.vicente.ros@uv.es (J.V.R.-L.) \\ 2 Institut de Ciència dels Materials (ICMUV), c/ Catedrático José Beltrán 2, Paterna, 46980 Valencia, Spain; \\ haskouri@uv.es \\ 3 Centro de Reconocimiento Molecular y Desarrollo Tecnológico (IDM), Unidad Mixta Universitat Politècnica \\ de València-Universitat de València, Departamento de Química, Universitat Politècnica de València, \\ Camino de Vera s/n, 46022 Valencia, Spain; mmarcos@qim.upv.es \\ * Correspondence: pedro.amoros@uv.es (P.A.); angeles.ubeda@uv.es (M.Á.Ú.); francisco.perez@uv.es (F.P.-P.); \\ Tel.: +34-963-543-617 (P.A.); +34-963-543-147 (M.Á.Ú.); +34-963-543-734 (F.P.-P.)
}

Received: 10 April 2020; Accepted: 20 April 2020; Published: 22 April 2020

\begin{abstract}
New catalysts based on $\mathrm{Pd}(0)$ nanoparticles (Pd NPs) on a bimodal porous silica of the UVM-7/polydopamine (PDA) support have been synthesized following two preparative strategies based on the sequential or joint incorporation of two components of the composite (Pd and PDA). We analyzed the role played by the PDA as 'interfacial glue' between the silica scaffold and the Pd NPs. The catalysts were tested for the hydrogenation of 4-nitrophenol using $\left(\mathrm{NEt}_{4}\right) \mathrm{BH}_{4}$ as the hydrogenating agent. In addition to the palladium content, the characterization of the catalysts at the micro and nanoscale has highlighted the importance of different parameters, such as the size and dispersion of the Pd NPs, as well as their accessibility to the substrate (greater or lesser depending on their entrapment level in the PDA) on the catalytic efficiency. Staged sequential synthesis has led to better catalytic results. The most active $\mathrm{Pd}(0)$ centers seem to be Pd NPs of less than $1 \mathrm{~nm}$ on the PDA surface. The efficiency of the catalysts obtained is superior to that of similar materials without PDA. A comprehensive comparison has been made with other catalysts based on Pd NPs in a wide variety of supports. The TOF values achieved are among the best described in the literature.
\end{abstract}

Keywords: mesoporous silica; bimodal porosity; polydopamine; palladium; nanoparticles; 4-nitrophenol; catalytic reduction

\section{Introduction}

The immobilization of metal nanoparticles (NPs) on inorganic, organic, or hybrid supports has attracted a considerable attention by their potential applications as efficient catalysts as it adds the classic advantages of the heterogeneous catalysis to the bottom-up approach of NP system [1]. The NPs immobilization is a challenge due to the loss of control in the interface where the metal-support interaction plays a key role in the synthesis of an efficient catalysts [2,3]. The modification of the support aimed at generating a suitable environment that controls the charge and dispersion of the metal NPs and that avoids their aggregation and leaching, is one of the most interesting approaches in the development of metal NPs supported catalysts [3].

Inspired by the adhesive proteins in mussels, Lee and coworkers synthesized the polydopamine (DPA) by oxidative self-polymerization at alkaline $\mathrm{pH}$ values of the low molecular weight biomolecule 
dopamine (DP). DP contains catechol and amine functional groups whose combination is related to the interfacial adhesion $[4,5]$.

PDA exhibits strong adhesion on virtually any surface by intensive covalent and noncovalent bindings [6]. This PDA capability has been used for a large variety of applications (in addition to catalysis) [7] and also as preparative tool to favor, for example, the formation of graphitized surfaces through pyrolysis [8]. Another important characteristics of PDA are its ability to coordinate to various metal ions by the phenol, o-quinone, carboxy, amino, and imine groups that contains, and to reduce metal salts within a solution into metal NPs via the catechol functional groups [6,9]. The adhesive property of PDA on any surface together with the ability of PDA to drive the interfacial assembly of metal NPs stabilizing them and avoiding the reduction of their activity, represents a new approach in the synthesis of effective metal NPs supported catalysts.

Following this approach some metal NPs-PDA-supported catalysts have been synthesized and efficiently tested in reduction of nitroarenes, oxidation of alcohols, and Susuky-Miyaura cross-coupling reactions (NPs of $\mathrm{Pt}, \mathrm{Pd}, \mathrm{Ag}$, and $\mathrm{Au}$, and SBA-15, hallosyte nanotubes, $\mathrm{Fe}_{3} \mathrm{O}_{4}$, carbon nanotubes, graphene, graphene oxide, $\mathrm{MoS}_{2}$, and $\mathrm{Au}$ as supports) [2,9-18].

The reduction of nitroarenes is one of the most used catalytic processes since the aniline and their derivatives represent a large part of the market in the organic chemical industry. This reaction implies the transformation of compounds of pollutant nature into intermediates in the industrial productions of agrochemicals, polymers, pharmaceuticals, dyes, and pigments [19-25].

The reduction by transfer hydrogenation of 4-nitrophenol with $\mathrm{NaBH}_{4}$ is a "model catalytic reaction" [26], it is well controlled reaction where a single product from a single reactant is obtained at mild temperatures and whose progress can be easily monitored by UV-visible spectrophotometry. This reaction has been accepted as a trusted model reaction to test the activity of metal NPs catalysts [27-29].

In a previous work, we have studied the activity of a catalyst Pd NPs-UVM-7 consisting of Pd NPs supported on silica UVM-7 [1]. In order to improve the dispersion and avoid the aggregation of the Pd NPs on the UVM-7 support, we have decorated the silica with PDA which will allow the interfacial assembly of the Pd NPs stabilizing them on the support. Different Pd NPs-UVM-7/PDA catalysts have been synthesized and characterized, and their activity have been studied using the model reaction of 4-nitrophenol reduction with $\mathrm{NEt}_{4} \mathrm{BH}_{4}$.

\section{Results and Discussion}

\subsection{Synthesis Design}

We have used two preparative strategies in order to incorporate both Pd and PDA on the bimodal pore systems of the UVM-7 silica (Figure 1) [30-33]. The main difference is based on the sequential or joint incorporation of two components of the composite (Pd and PDA). The first strategy (Pathway a) corresponds to a 'two-pot' methodology in which in a first step the silica surface is covered with PDA (through polymerization of the DA in a tamponed medium). During the second step the incorporation of $\mathrm{Pd}(\mathrm{II})$ is carried out by using $\mathrm{H}_{2}\left[\mathrm{PdCl}_{4}\right]$ or $\mathrm{K}_{2}\left[\mathrm{PdCl}_{4}\right]$ complexes as metal source followed by the reduction with $\mathrm{NaBH}_{4}$ to favor the $\mathrm{Pd}(0)$ particle formation. Three catalysts have been prepared through this Pathway a: Pd NPs-UVM-7/PDA-n (n= 1, 2, and 3).

The alternative strategy could be viewed as a 'one-pot' route in which both the DA polymerization and the Pd(II) incorporation was made simultaneously (Pathway b). As in the 'two-pot' method, a final reduction process by using $\mathrm{NaBH}_{4}$ was applied. Two catalysts have been prepared through this Pathway b: Pd NPs-UVM-7/PDA-n ( $\mathbf{n}=\mathbf{4}$ and 5).

Pathway $a$ has been split into two others depending on the material on which the reducing agent is added. In a case, the excess of $\operatorname{Pd}(\mathrm{II})$ was removed by centrifugation prior to the chemical reduction. For this synthesis, only the $\operatorname{Pd}(\mathrm{II})$ species anchored on the surface were finally candidates to be transformed to $\operatorname{Pd}(0)$ particles. Consequently, a lower $\mathrm{Pd}$ content was expected for this synthesis 
(Catalysts Pd NPs-UVM-7/PDA-1). On the contrary, if this centrifugation (separation) stage is avoided, the excess of $\mathrm{Pd}(\mathrm{II})$ in the reaction media (well solubilized, in suspension and weakly connected to PDA) is susceptible to be reduced leading to $\mathrm{Pd}(0)$ particles. Obviously, this method produces final composites richest in Pd (Catalysts Pd NPs-UVM-7/PDA-n $(\mathbf{n}=\mathbf{2}, \mathbf{3})$ ) when compared to the catalyst Pd NPs-UVM-7/PDA-1. By using $\mathrm{H}_{2}\left[\mathrm{PdCl}_{4}\right]$ as Pd source, and similar reagents proportions, the centrifugation step decreases the final Pd content in ca. $50 \%$. (from Si/Pd $=383$ to Si/Pd $=768$ for samples Pd NPs-UVM-7/PDA-n, $\mathbf{n}=\mathbf{3}$ and $\mathbf{n}=\mathbf{1}$, respectively). The incorporation of Pd can be increased by using $\mathrm{K}_{2}\left[\mathrm{PdCl}_{4}\right](\mathrm{Si} / \mathrm{Pd}=92)$ even starting of a lower nominal amount of $\mathrm{PdCl}_{2}(\mathrm{Pd}$ NPs-UVM-7/PDA-2).

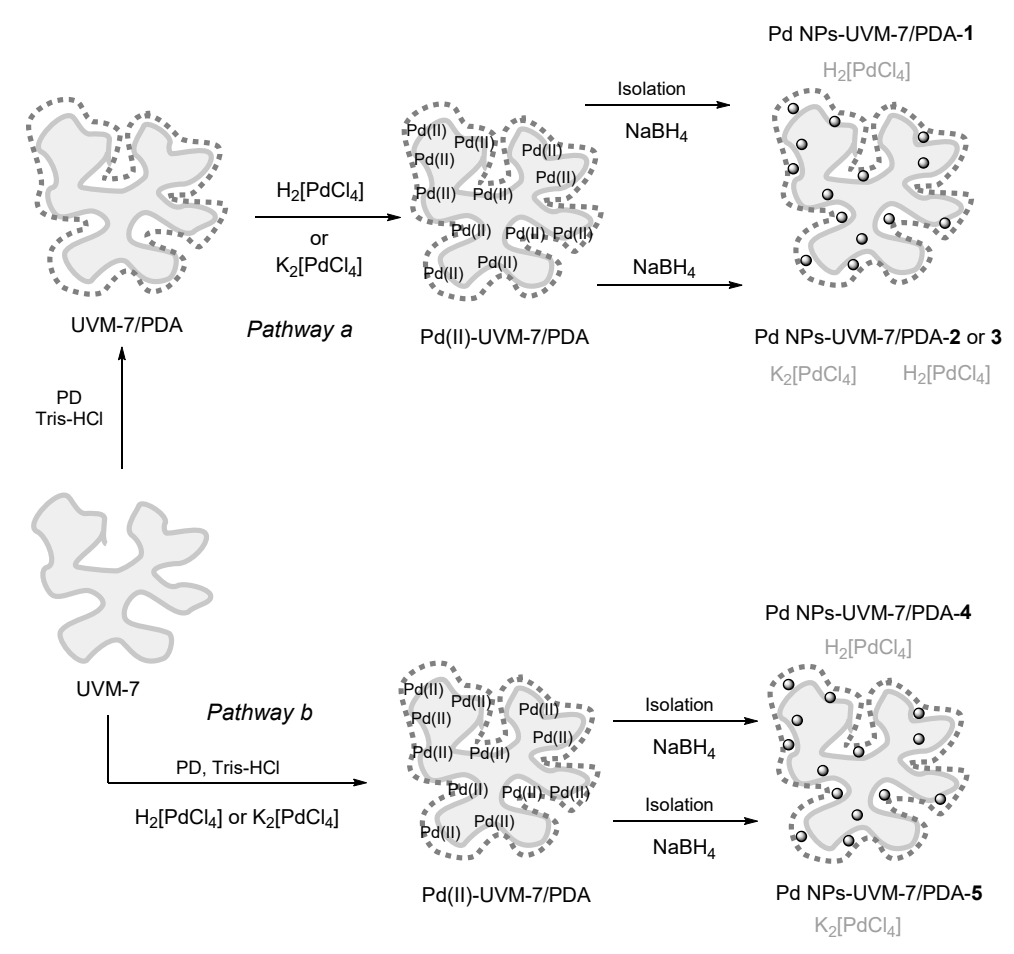

Figure 1. Synthesis scheme showing the two strategies or preparatory paths used: Pathway a ('two-pot' method) and Pathway b ('one-pot' method).

In the case of Pathway b, the Pd(II) species were anchored on the surface or embedded inside the PDA and not much excess of $\mathrm{Pd}$ (II) was removed by the centrifugation prior to the chemical reduction. Pd NPs-UVM-7/PDA-n ( $\mathbf{n}=4$ and 5) showed a high Pd content ( $\mathrm{Si} / \mathrm{Pd}=44$ and 41 respectively). The $\mathrm{Pd}$ source $\left(\mathrm{H}_{2}\left[\mathrm{PdCl}_{4}\right]\right.$ or $\left.\mathrm{K}_{2}\left[\mathrm{PdCl}_{4}\right]\right)$, seems to be irrelevant on the final Pd incorporation.

\subsection{Catalysts Characterization}

We combined TGA and EDX data in order to obtain the approximate formulation of the different catalysts. All TGA curves shows an initial and moderate weight loss at low temperature (up to ca. $100{ }^{\circ} \mathrm{C}$ ) that only can be attributed to water molecules inside the bimodal pore systems. The PDA pyrolysis occurs in a two-step overlapped process in the $100-900{ }^{\circ} \mathrm{C}$ temperature range. All catalysts show TGA curves with very-similar shapes (see Figure S1). Based on the TGA data we estimated the PDA amount. On the other hand, the EDX analysis allows us to obtain the Pd content (referred to the Si amount). This information is gathered in Table 1.

The tendencies, previously mentioned dealing with the preparative pathways, on the expected compositions are supported by data of Table 1. Pathway a leads (for similar syntheses) to lower $\operatorname{Pd}(0)$ contents than the Pathway $b$. The lowest Pd content corresponds to the Pd NPs-UVM-7/PDA-1 catalysts where, in addition, the excess of $\mathrm{Pd}(\mathrm{II})$ was separated through centrifugation. In this case, only a low 
amount of Pd(II) complexes, strongly connected to the PDA surface, finally generates the Pd NPs. In the case of the Pathway b, no significant differences in the Pd content occur. The 'one-pot' method covers the UVM-7 silica surface with PDA polymer in which the $\mathrm{Pd}(\mathrm{II})$ species result embedded in a large proportion regardless the Pd complex used.

The IR spectra of the catalysts confirm that the silica architecture has been coated with PDA (Figure S2). As the silica counterpart is the majority component of the catalysts, the typical IR bands of the UVM-7 silica remains as the most intense ones: peaks observed at 1060 and 1210, 795, and $970 \mathrm{~cm}^{-1}$ can be unambiguously assigned to $v_{\text {as }}(\mathrm{Si}-\mathrm{O}-\mathrm{Si}), v_{\mathrm{s}}(\mathrm{Si}-\mathrm{O}-\mathrm{Si})$, and $v_{\mathrm{s}}(\mathrm{Si}-\mathrm{OH})$ vibration modes, respectively. All catalysts show IR spectra with a wide absorption band at $3370 \mathrm{~cm}^{-1}$ which can be attributed to the $v(\mathrm{OH})$ and $v(\mathrm{NH})$ vibration modes of the PDA, where the vibrations of water molecules, obviously also contribute. However, where the fingerprint of the PDA results unambiguous is in the 1700-1300 $\mathrm{cm}^{-1}$ energy range: well defined bands are observed at ca. 1627, 1552, 1414, and $1345 \mathrm{~cm}^{-1}$ assigned to $v(\mathrm{C}=\mathrm{O}), v(\mathrm{C}=\mathrm{N}), v\left(\mathrm{NH}_{3}\right)$, and $\delta(\mathrm{C}-\mathrm{N}-\mathrm{C})$ vibration modes, respectively [34,35].

Table 1. Compositional data of the Pd NPs-UVM-7/PDA-n catalyst

\begin{tabular}{|c|c|c|c|}
\hline $\begin{array}{c}\text { Catalyst } \\
\mathbf{n}\end{array}$ & $\begin{array}{c}\text { Si/Pd }{ }^{1} \\
\text { Molar Ratio }\end{array}$ & $\begin{array}{c}\text { PDA Content }^{2} \\
(w t \%)\end{array}$ & $\begin{array}{l}\text { Water Content } \\
\quad(w t \%)\end{array}$ \\
\hline 1 & 768 & 10 & 2 \\
\hline 2 & 92 & 13 & 3 \\
\hline 3 & 383 & 7 & 2 \\
\hline 4 & 44 & 21 & 3 \\
\hline 5 & 41 & 9 & 2 \\
\hline
\end{tabular}

${ }^{1}$ Values determined by EDX. ${ }^{2}$ Values determined through the TGA curves.

Once the presence and content of the catalyst components has been determined, we will analyze their distribution at the nano-scale combining HRTEM, HAADF, STEM-mapping, XRD, and adsorption desorption $\mathrm{N}_{2}$ isotherms. TEM and HRTEM images of selected catalysts are shown in Figure 2. Figure 2a shows that the typical architecture of the UVM-7 silica (the core of the composite) is preserved [33]. In fact, in this image it is possible to appreciate the clustered morphology formed through mesoporous nanoparticle aggregation. However, the edges of the nanoparticles appear somewhat smoother, when compared to pure silica. This could be due to PDA coverage. The HRTEM images of the Pd NPs-UVM-7/PDA-n clearly display the presence of ordered nanodomains which correspond to the Pd NPs. The solids synthesized trough the Pathway a display Pd NPs with lower size and aggregation level (Pd NPs-UVM-7/PDA-n $(\mathbf{n}=\mathbf{1}, \mathbf{2})$; Figure $2 \mathbf{b}, \mathrm{c})$ than the catalysts prepared by the Pathway $b$ (Pd NPs-UVM-7/PDA-5; Figure 2d). On the other hand, the isolation by centrifugation to eliminate the excess of $\mathrm{Pd}(\mathrm{II})$ in Pathway a also affect, as expected, the aggregation level. This effect results evident when images in Figure 2b (Pd NPs-UVM-7/PDA-1) and 2c (Pd NPs-UVM-7/PDA-2) are compared, these processed with and without centrifugation, respectively. Taking into account that during the Pd NPs-UVM-7/PDA-5 catalyst preparation the centrifugation step was also used, the large Pd NPs aggregates observed in Figure $2 \mathrm{~d}$ must be undoubtedly associated to the 'one-pot' strategy, in which the PDA trap in a quickly way the Pd complexes and the subsequent formed Pd NPs. However, in all cases the increase in the size of the Pd domains is due more to the aggregation of small nanoparticles than to particle growth. 

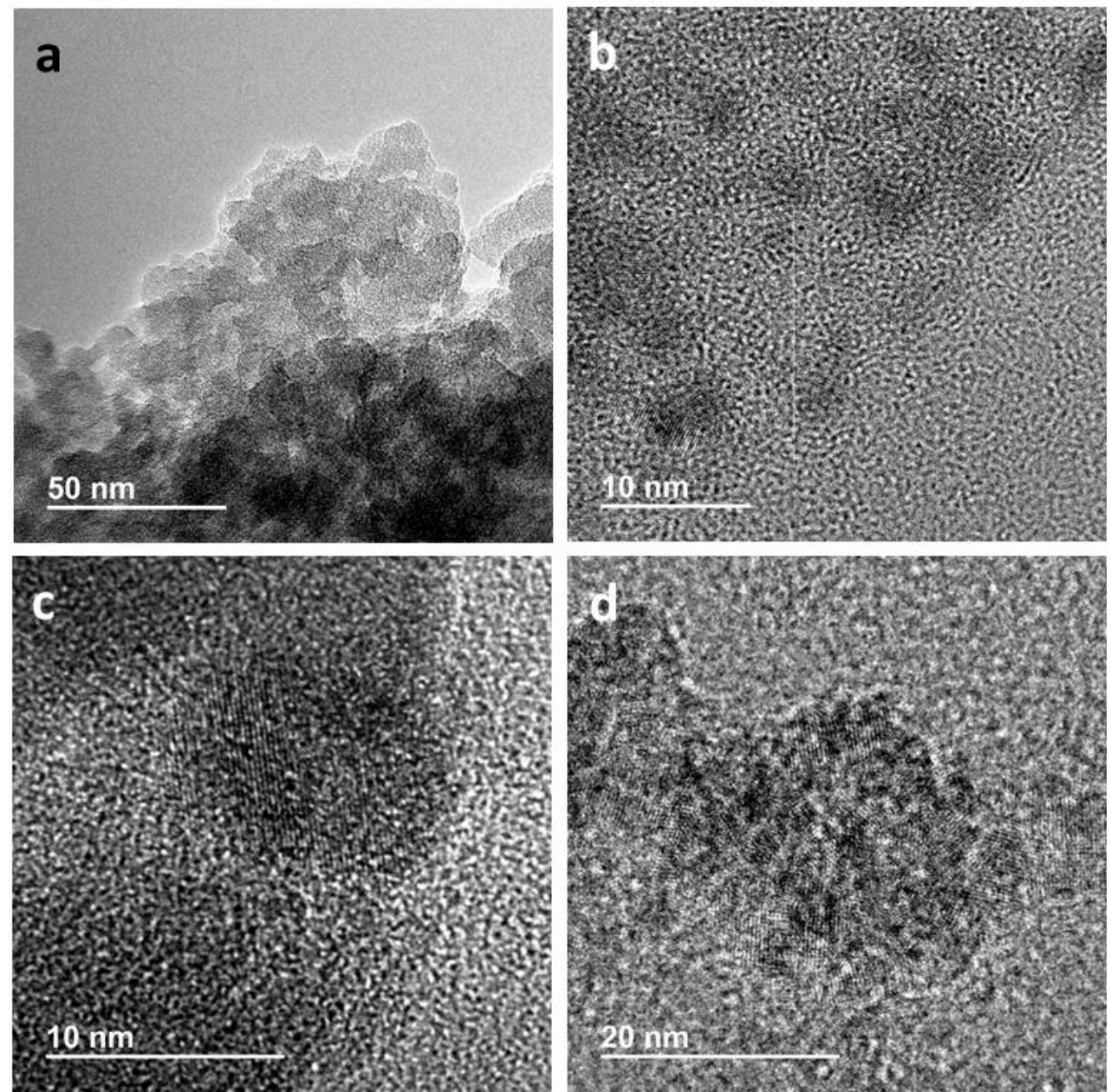

Figure 2. TEM images of selected catalysts.

(a) TEM and (b) HRTEM micrographs of the Pd NPs-UVM-7/PDA-1 catalyst. HRTEM images of the Pd NPs-UVM-7/PDA-2 (c) and Pd NPs-UVM-7/PDA-5 (d) catalysts.

In order to determine in a more precise way both the average size of the Pd NPs and the distribution of the three components of the composite-catalysts (silica, PDA, and Pd) a study by STEM-HAADF has been carried out. Figure 3 includes data corresponding to catalysts isolated by the Pathway a. The Pd NPs distribution in catalyst Pd NPs-UVM-7/PDA-1 shows a certain heterogeneity, combining rich (Figure 3a) and very-poor (Figure 3b) Pd NPs zones. Notwithstanding, in all the Pd-rich domains a high nanoparticle size homogeneity occurs, with a very narrow particle size distribution centered at ca. $1 \mathrm{~nm}$ (Figure 3c). The EDX mapping (Figure 3b) shows homogeneous distributions of Si (from the UVM-7 silica) and N (from the PDA), which indicates a good polymer covering on the silica surface. Interestingly, we also detect the presence of Pd in domains absent of bright spots by HAADF. These observations suggest the possible presence of $\mathrm{Pd}(\mathrm{II})$ complexes embedded or trapped in the PDA. In the case of the Pd NPs-UVM-7/PDA-2 catalyst (Figure 3c,d), together with the previously mentioned irregular dispersion of the Pd NPs, we detect also a higher nanoparticle size heterogeneity (with a wider distribution centered at ca. $1.5 \mathrm{~nm}$ that is extending up to $7-8 \mathrm{~nm}$ ). 

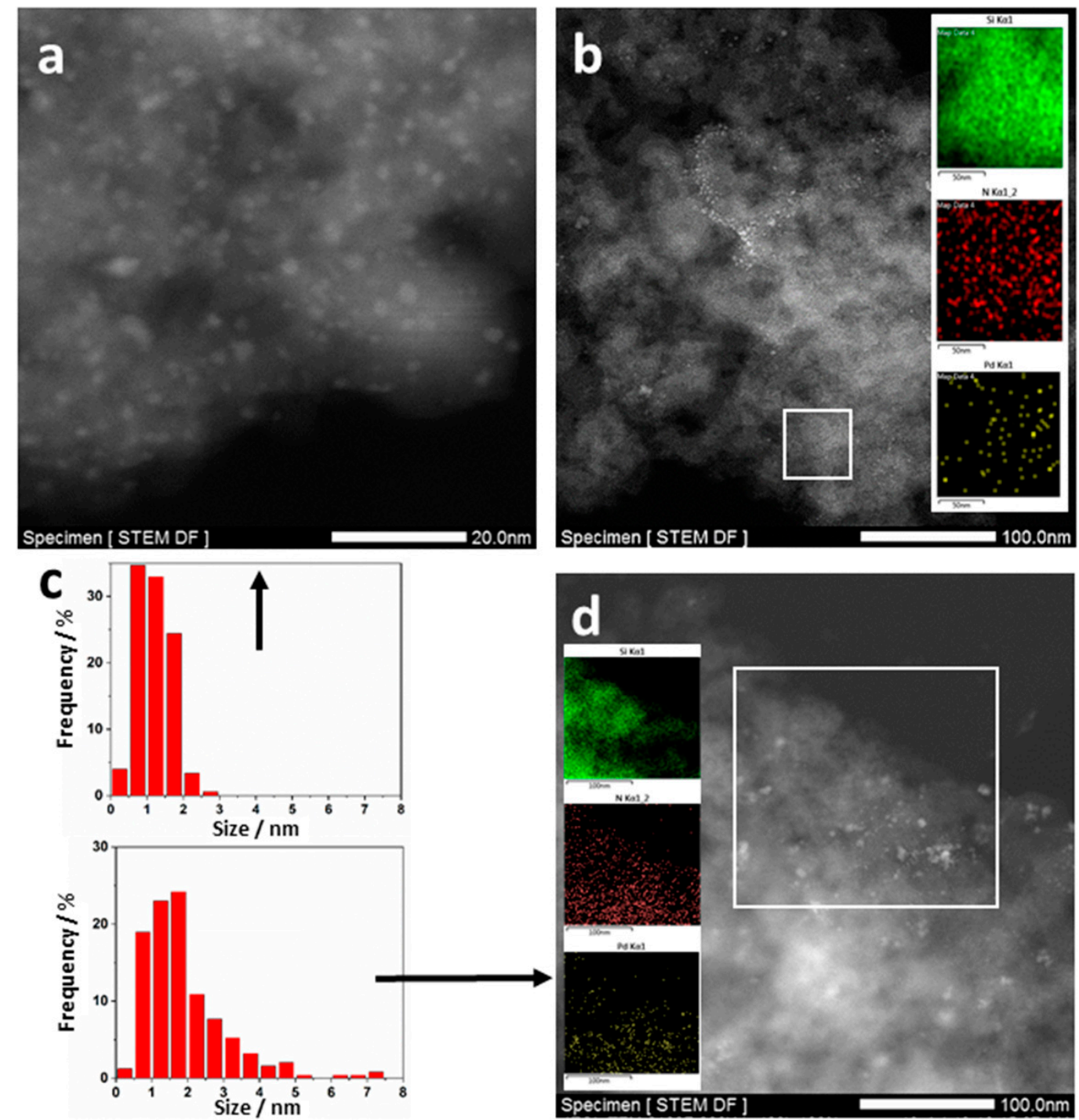

Figure 3. (a) HAADF-STEM image of the Pd NPs-UVM-7/PDA-1 catalyst. (b) HAADF-STEM image of the Pd NPs-UVM-7/PDA-1 catalyst including an EDX mapping of the selected area showing the $\mathrm{Si}, \mathrm{N}$, and Pd distribution. (c) Histograms showing the Pd NPs size distribution (top and bottom graphics correspond to the Pd NPs-UVM-7/PDA-1 and Pd NPs-UVM-7/PDA-2 catalysts, respectively). (d) HAADF-STEM image of the Pd NPs-UVM-7/PDA-2 catalyst including an EDX mapping of the selected area.

In the case of the catalysts synthesized through the Pathway $b$, a large heterogeneity both in dispersion and especially in particle size distribution is detected. The images in Figure $4 a, b$, together with the wider particle size distributions in Figure $4 c, d$, show that a significant aggregation of the individual Pd NPs occurs. Moreover, as previously commented for the catalysts prepared by the Pathway $a$, if the excess of $\operatorname{Pd}(\mathrm{II})$ is not eliminated, the proportion of small particles decreases while the large clusters formation increases. This effect is slightly more pronounced in the case of $\mathrm{Pd}$ NPs-UVM-7/PDA-5 catalyst (isolated from $\mathrm{K}_{2}\left[\mathrm{PdCl}_{4}\right]$ complexes as Pd source). 

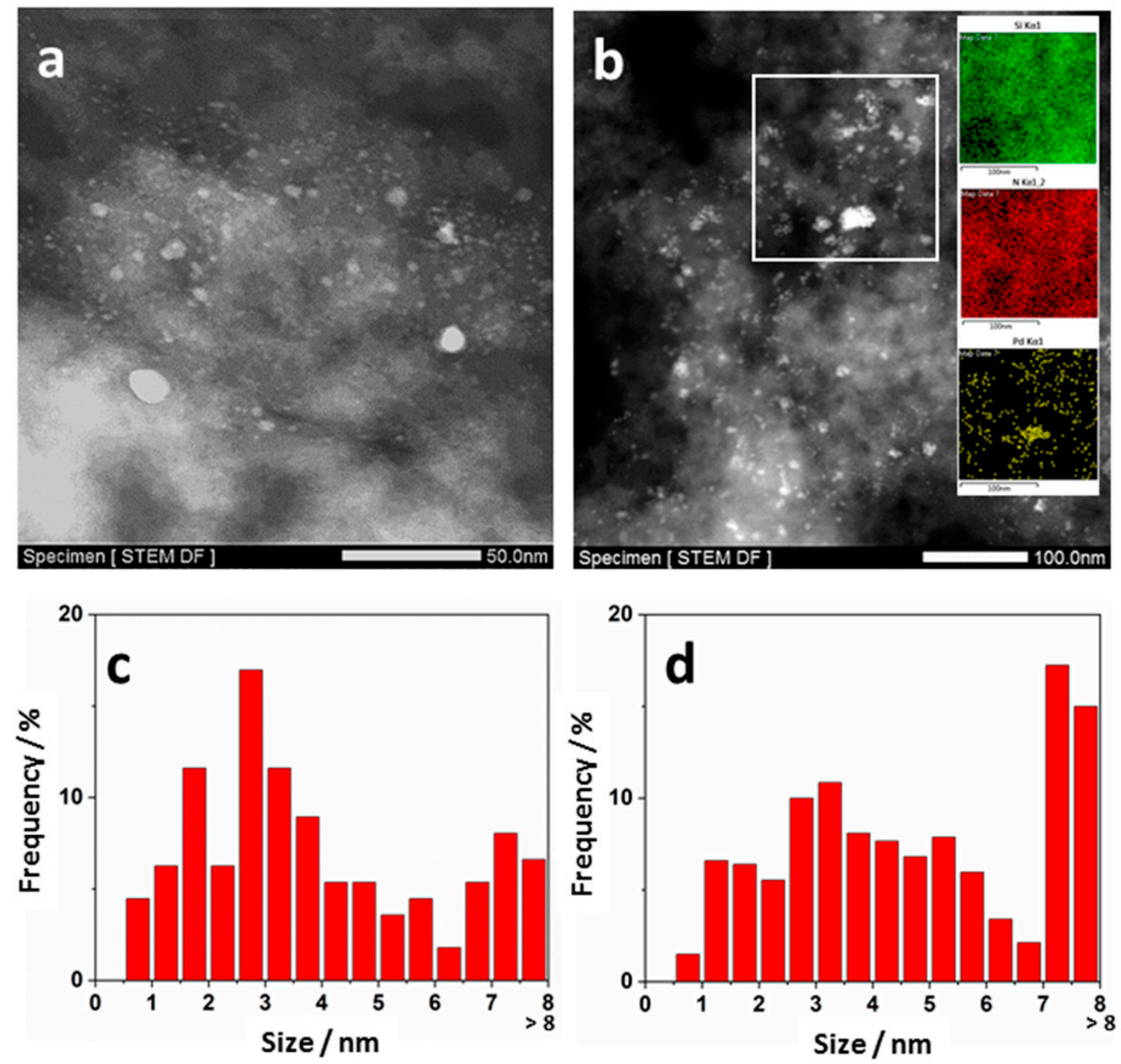

Figure 4. (a) HAADF-STEM image of the Pd NPs-UVM-7/PDA-4 catalyst. (b) HAADF-STEM image of the Pd NPs-UVM-7/PDA-5 catalyst including an EDX mapping of the selected area showing the Si, N, and Pd distribution. (c) Histogram showing the Pd NPs size distribution in the Pd NPs-UVM-7/PDA-4 catalyst. (d) Histogram showing the Pd NPs size distribution in the Pd NPs-UVM-7/PDA-5 catalyst.

The absence of XRD peaks in the high-angle range (Figure S3) is in good accordance with the TEM data. The small size of the Pd individual crystallites together with its low proportion precludes its detection by diffraction techniques. The only signals seen on the diffractograms appear at low angles and correspond to the mesostructure of the UVM-7 silica core (Figure S4). The observed signal can be assigned to the (100) reflection if a hexagonal MCM-41-type cell is assumed [36]. The width of this signal is typical of hexagonal disordered mesoporous arrays of the UVM-7 type [33]. Its decrease in intensity is related to the loss of contrast due to the incorporation of PDA in the mesopores. In fact, in the case of the PDA-richest catalysts (Pd NPs-UVM-7/PDA-n, $\mathbf{n}=\mathbf{2}, \mathbf{4}$ ) only a shoulder is observed.

Once the UVM-7 mesostructure order seems to be conserved as a scaffold about which the additional components were incorporated, we will investigate the preservation of the bimodal porosity by recording $\mathrm{N}_{2}$ adsorption-desorption isotherms. All the catalysts show curves with two well defined adsorption steps at medium $\left(\mathrm{P} / \mathrm{P}_{0}<0.3-0.5<\mathrm{P} / \mathrm{P}_{0}\right)$ and high $\left(\mathrm{P} / \mathrm{P}_{0}>0.8\right)$ relative pressure values that are associated with the filling with $\mathrm{N}_{2}$ by capillarity of the intraparticle mesopores and the large interparticle voids, respectively (Figure 5). High BET surface areas, $600-1025 \mathrm{~m}^{2} / \mathrm{g}$, has been estimated with the exception of the PDA-richest catalyst (Table 2). A gradual decrease of pore volume and surface area values with the PDA content occurs. Both the intra and interparticle porosity is preserved in a significant way up to PDA contents around $13 \mathrm{wt} \%$, independently of the preparative Pathway used 
( $a$ or $b$ ). The lower size of the monomer (DA) when compared to the mesopore size, and the short mesopore length of the UVM-7 (at most of the order of the silica particle size, ca. 30-50 nm) are factors that cooperatively favor an easy diffusion and dispersion of the DA molecules along both pore systems. Then, the subsequent polymerization must occur homogeneously on all silica surfaces (inner and exterior), hindering the excessive pore filling or undesired pore-blocking phenomena. Nonetheless, the most significant aspect is that all catalysts preserve in a large extent the starting bimodal porosity of the UVM-7 material.

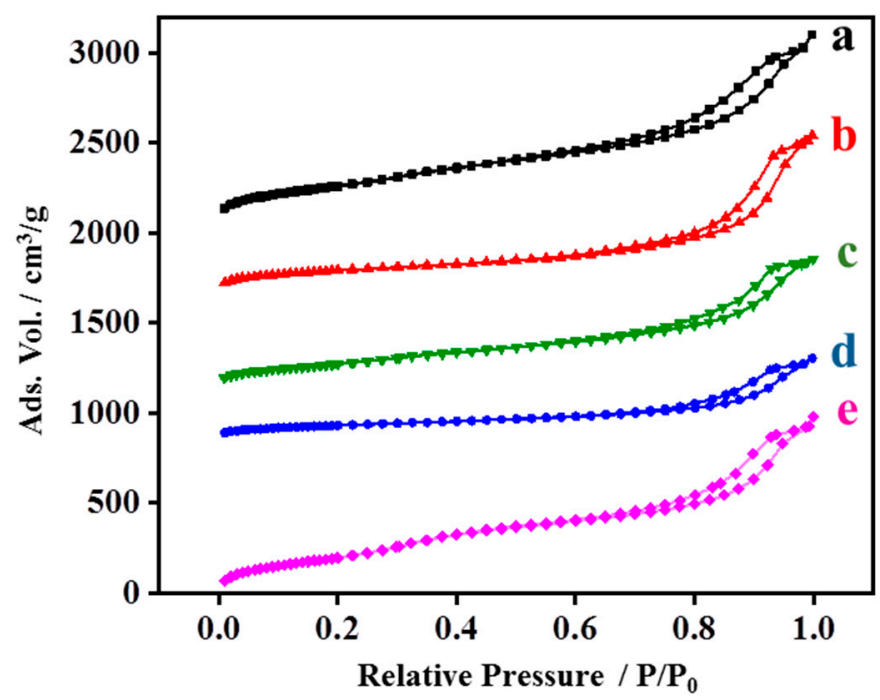

Figure 5. $\mathrm{N}_{2}$ adsorption-desorption isotherms of the Pd NPs-UVM-7/PDA-n catalysts. (a) $\mathbf{n}=\mathbf{1}$, (b) $\mathbf{n}=\mathbf{2}$, (c) $\mathbf{n}=3$, (d) $\mathbf{n}=4$, and (e) $\mathbf{n}=\mathbf{5}$. (curves has been $y$-shifted for clarity: (a) 2080, (b) 1660, (c) 1130 , and (d) $\left.830 \mathrm{~cm}^{3} / \mathrm{g}\right)$.

Table 2. Textural parameters of the pure UVM-7 silica and the Pd NPs-UVM-7/PDA-n catalysts

\begin{tabular}{ccccccc}
\hline $\begin{array}{c}\text { Catalyst. } \\
\mathbf{n}\end{array}$ & $\begin{array}{c}\mathbf{d}_{\mathbf{1 0 0}} \mathbf{1} \\
\mathbf{n m}\end{array}$ & $\begin{array}{c}\text { Surface Area } \\
\mathbf{m}^{\mathbf{2}} / \mathbf{g}\end{array}$ & $\begin{array}{c}\text { Mesopore Size } \\
\mathbf{n m}\end{array}$ & $\begin{array}{c}\text { Mesopore Volume } \\
\mathbf{c m}^{\mathbf{3}} \mathbf{g}\end{array}$ & $\begin{array}{c}\text { Large Pore Size }^{\mathbf{4}} \\
\mathbf{n m}\end{array}$ & $\begin{array}{c}\text { Large Pore Volume }^{\mathbf{4}} \\
\mathbf{c m}^{\mathbf{3}} / \mathbf{g}\end{array}$ \\
\hline UVM-7 & 4.3 & 1100 & 2.86 & 0.95 & 27.3 & 1.62 \\
1 & 4.6 & 998 & 2.54 & 0.61 & 13.7 & 1.32 \\
2 & shoulder & 628 & 2.50 & 0.41 & 16.6 & 1.21 \\
3 & 4.5 & 604 & 2.60 & 0.42 & 13.6 & 0.88 \\
4 & shoulder & 376 & 2.66 & 0.27 & 18.2 & 0.60 \\
5 & 4.5 & 1026 & 2.53 & 0.70 & 10.9 & 0.96 \\
\hline
\end{tabular}

${ }^{1}$ Values determined by XRD. ${ }^{2}$ Values determined by applying the BET model. ${ }^{3}$ Values determined by applying the BJH model on the adsorption branch of the isotherms $\left(\mathrm{P} / \mathrm{P}_{0}<0.8\right) .{ }^{4}$ Values determined by applying the BJH model on the adsorption branch of the isotherms $\left(\mathrm{P} / \mathrm{P}_{0}>0.8\right)$.

\subsection{Catalyst Activity}

The catalytic activity of materials was tested against the hydrogenation of 4-nitrophenol using $\left(\mathrm{NEt}_{4}\right) \mathrm{BH}_{4}$ as the hydrogenating agent. Formally, the hydrogenation can be described in diluted solution by the simplified process shown in Scheme 1, based on the electrochemical model of Haber [37,38]. This pathway consists of three consecutive reactions leading to the formation of a 4-aminophenol from the N-(4-hidroxyphenyl)hydroxylamine through the corresponding nitroso derivative. The overall reaction associated to the pathway was described by the following reaction:

$$
\mathrm{HO}-\mathrm{C}_{6} \mathrm{H}_{4}-\mathrm{NO}_{2}+6 \mathrm{H}_{2} \rightarrow \mathrm{HO}-\mathrm{C}_{6} \mathrm{H}_{4}-\mathrm{NH}_{2}+2 \mathrm{H}_{2} \mathrm{O}
$$

The literature suggests that reduction of 4-nitrophenol with borohydride is simple enough to be used as a suitable model for activity comparison [14,18,27-29,39]. For this system the intermediate products-i.e., N-(4-hydroxyphenyl)hydroxylamine and 4-nitrosophenol-reduce so rapidly that only 4-aminophenol is detected. Despite its apparent simplicity, the rate law for this heterogeneous 
reduction depends heavily on the catalyst used. In this regard, the reaction is usually described as first-order, but there is a strong evidence that the rate law is more complicated due to the nitroarene and hydride adsorption phenomena on the Pd surface [28,40].

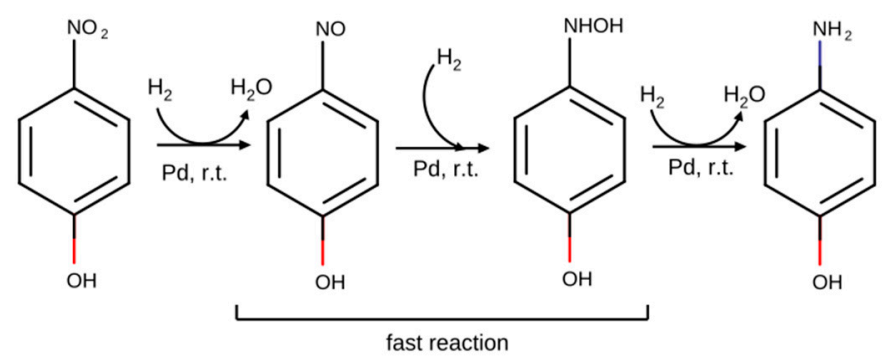

Scheme 1. Hydrogenation mechanism leading to the formation of a 4-aminophenol from the $\mathrm{N}$-(4-hidroxyphenyl)hydroxylamine

Figure 6 shows the absorbance change for the reduction of 4-nitrophenolate to 4-aminophenolate catalysed by the Pd NPs-UVM-7/PDA-1 material. The reaction was monitored at $402 \mathrm{~nm}$ (absorption maximum of 4-nitrophenolate) as 4-nitrophenol and 4-aminophenol were found as 4-nitrophenolate $\left(\mathrm{pK}_{\mathrm{a}}=7.15\right)$ and 4-aminophenolate $\left(\mathrm{pK}_{\mathrm{a}, 1}=5.48, \mathrm{pK}_{\mathrm{a}, 2}=10.3\right)$ in the basic medium provided by the reaction of excess $\mathrm{BH}_{4}{ }^{-}$with water $\left(\mathrm{H}^{-}+\mathrm{H}_{2} \mathrm{O} \rightarrow \mathrm{H}_{2}+\mathrm{OH}^{-}\right)$. The inset shows the variation of $-\ln (\alpha)$ vs. time (vide infra Equation (1)) for the Pd NPs-UVM-7/PDA-1 comparing with that obtained for Pd NPs-UVM-7 (without PDA). It can be seen that the first material presents first-order kinetics, whereas this is far from being true for the Pd NPs-UVM-7 catalyst. As stated, not all studied reactions follow a first-order rate law.

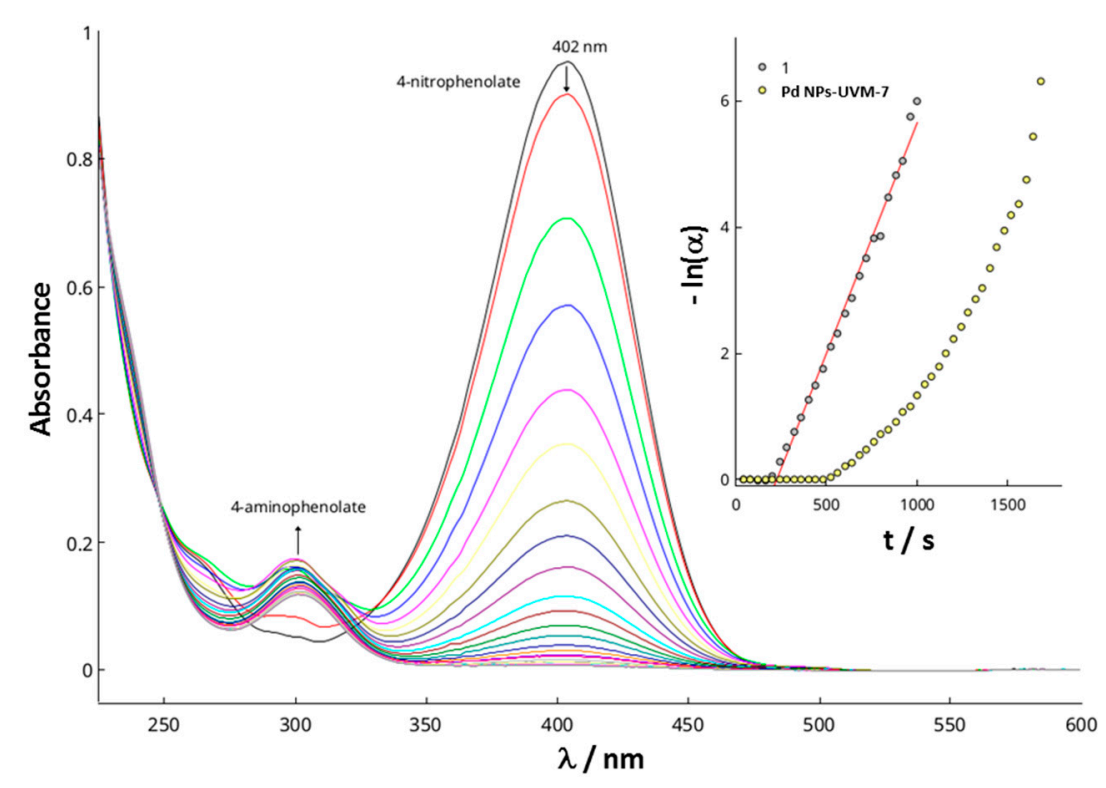

Figure 6. Variation of absorbance during the reduction at room temperature of 4-nitrophenolate with $\left(\mathrm{Et}_{4} \mathrm{~N}\right) \mathrm{BH}_{4}$ catalyzed by material Pd NPs-UVM-7/PDA-1. Inset: Plot of $-\ln (\alpha)$ vs. time for materials Pd NPs-UVM-7/PDA-1 and Pd NPs-UVM-7. Pd NPs-UVM-7/PDA-1 shows pseudo-first-order kinetics $\left(k=7.3 \times 10^{-3} \mathrm{~s}^{-1}\right)$, in contrast with Pd NPs-UVM-7. Initial composition (both systems): $\left[\mathrm{NO}_{2} \mathrm{PhO}^{-}\right]=5.02 \times 10^{-5} \mathrm{M} ;\left[\left(\mathrm{Et}_{4} \mathrm{~N}\right) \mathrm{BH}_{4}\right]=2.0 \times 10^{-2} \mathrm{M} ;[\mathrm{Pd}]=6.3 \times 10^{-8} \mathrm{M}$. Reaction medium: acetonitrile: water $1: 1 \mathrm{v} / \mathrm{v}$. 
Figure 7 shows the relative concentration of 4-nitrophenolate calculated from the absorbance $(A)$ using Equation (1), [29,41]

$$
\alpha(t)=\frac{A_{t}-A_{\infty}}{A_{0}-A_{\infty}}
$$

The use of Equation (1) instead of $A_{t} / A_{0}$ is strongly recommended to estimate the relative concentration of 4-nitrophenolate, since the subtraction of $A_{\infty}$ corrects the background absorbance originated by the catalyst. The reaction exhibits an induction period $\left(t_{\text {ind }}\right)$ during which the substrate concentration remains virtually constant, and from here, reduction proceeds until the exhaustion of the 4-nitrophenolate. The induction period is due to the oxidation of 4-aminophenol by the $\mathrm{O}_{2}$ dissolved in medium, specially in the PDA layer [42].

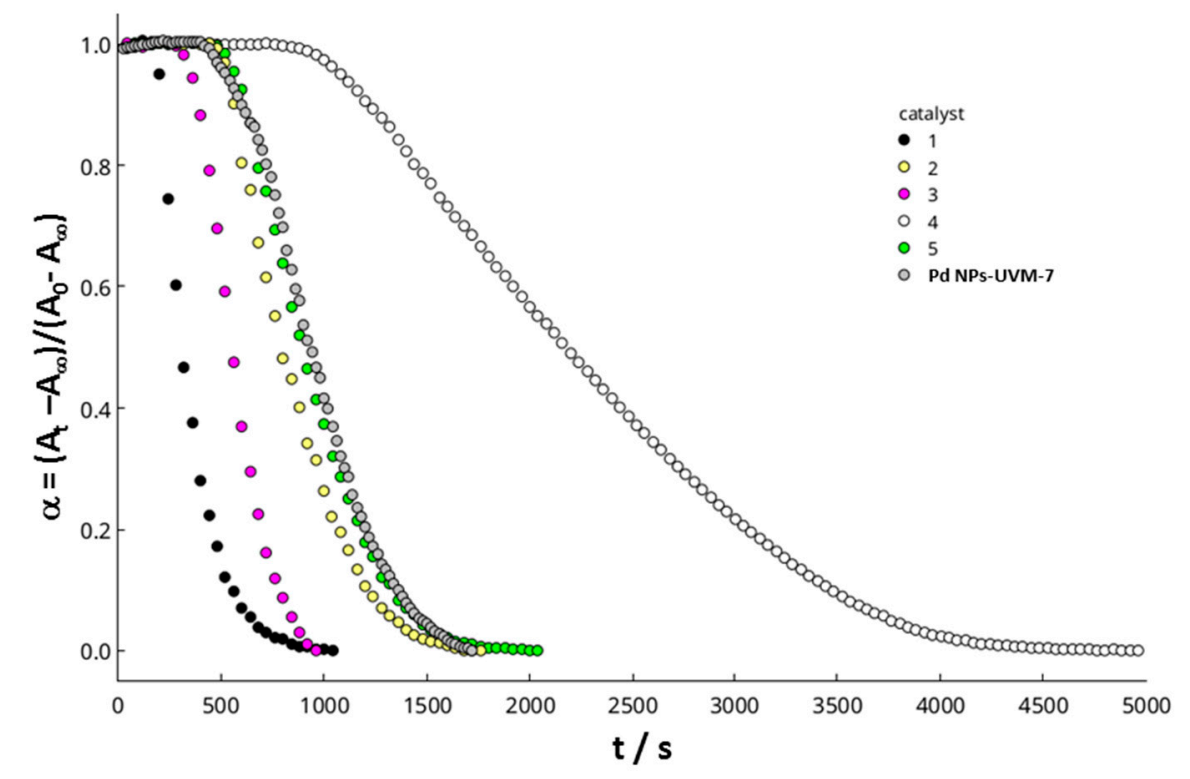

Figure 7. $\alpha(\mathrm{t})$ values calculated from absorbance at $402 \mathrm{~nm}$ during the reduction at room temperature of 4-nitrophenolate with $\left(\mathrm{Et}_{4} \mathrm{~N}\right) \mathrm{BH}_{4}$ catalyzed by materials Pd NPs-UVM-7/PDA-n (n = $\mathbf{1}$ to 5$)$ and Pd NPs-UVM-7; $\left[\mathrm{NO}_{2} \mathrm{PhO}^{-}\right]=5.02 \times 10^{-5} \mathrm{M} ;\left[\left(\mathrm{Et}_{4} \mathrm{~N}\right) \mathrm{BH}_{4}\right]=2.0 \times 10^{-2} \mathrm{M} ;[\mathrm{Pd}]=6.3 \times 10^{-8} \mathrm{M}$. Reaction medium: acetonitrile: water $1: 1 \mathrm{v} / \mathrm{v}$.

In order to estimate the activity, the half-life time $\left(\alpha\left(\mathrm{t}^{\prime}{ }_{1 / 2}\right)=0.5\right)$ was determined graphically and corrected by subtracting the induction time $\left(t_{1 / 2}=t_{1 / 2}^{\prime}-t_{\text {ind }}\right)$, see Figure S5 for details in the Supplementary Information. At the half-life, the average turn-over frequency is defined according to Equation (2), where $[\mathrm{C}]$ is the concentration of catalyst and $\mathrm{k}$ the pseudo first-order rate constant,

$$
\mathrm{TOF}_{1 / 2}=\frac{\left[\mathrm{NO}_{2} \mathrm{PhO}^{-}\right]_{0} \times 0.5}{t_{1 / 2} \times[\mathrm{C}]}=\frac{\left[\mathrm{NO}_{2} \mathrm{PhO}^{-}\right]_{0} \times 0.5 \times k}{\ln (2) \times[\mathrm{C}]}
$$

The second member of Equation (2) only applies if reactions follow first-order kinetics. This method is entirely analogous to that developed by Larm et col. [38] for the purpose of comparing the catalytic activity of $\mathrm{Au}$ NPs reported from various sources, except that the left hand of Equation (2) does no require the reaction to be first-order.

The procedure was applied to all prepared materials. The corrected half-life times and $\mathrm{TOF}_{1 / 2}$ for 4-nitrophenolate were collected in Table 3. Figure 8 shows that $\mathrm{TOF}_{1 / 2}$ correlates to the $\mathrm{Si} / \mathrm{Pd}$ ratio with the exception of Pd NPs-UVM-7/PDA-4. The result is somewhat surprising, as it suggests that activity increases as the Pd load of the material decreases. Although it is evident that the active centers are the $\operatorname{Pd}(0)$ particles, different aspects such as their average size, dispersion, and accessibility may be key parameters, and even more important than the palladium amount. It can be seen that materials 
prepared through the process involving PDA coating followed by $\mathrm{Pd}(\mathrm{II})$ deposition/reduction are more active than those prepared by one-pot methodology. A likely explanation is that catalysts prepared by the one-pot process introduce a large Pd amount in the bulk of the PDA layer, making a part of the metal inaccessible to nitroarene adsorption. From our data, the most efficient active sites seem to be the smaller Pd NPs, with sizes around $1 \mathrm{~nm}$. These centers are the dominant ones in the Pd NPs-UVM-7/PDA-1 catalyst, although certain heterogeneity has been observed by electron microscopy, with Pd-rich zones and other domains where the Pd Nps are absent. In any case, no heterogeneity dealing with the nanoparticle size is detected, and a narrow size distribution is observed. Curiously, this Pd NPs-UVM-7/PDA-1 catalyst contains by far, the lower Pd concentration. This suggests that these very small Pd NPs are truly very active catalytic centers. In contrast, preparation as a 'one-pot' route mainly accumulate the Pd on the polymer surface (Pd NPs-UVM-7/PDA-n ( $n=4$ and 5$)$ ). In this case, the proportion of small-sized Pd NPs decreases significantly and bigger particles and large aggregates larger than $10 \mathrm{~nm}$ are observed. This already could justify a lower catalytic activity. In addition, it must be borne in mind that a large part of the Pd NPs can be completely embedded by the PDA, which could further reduce its catalytic capacity. In the case of Pd NPs-UVM-7/PDA-4 catalyst, the higher proportion of PDA (approximately double that of the rest of composites), will minimizes the number of accessible active sites, and consequently this composite is the worst catalyst. On the other hand, the comparison of the catalytic activity of Pd NPs-UVM-7/PDA-1 and Pd NPs-UVM-7, indicates that the incorporation of PDA to the catalyst has a beneficial effect for the reactions tested.

Table 3. Half-life times for the reduction of 4-nitrophenol by $\left(\mathrm{Et}_{4} \mathrm{~N}\right) \mathrm{BH}_{4}$ in water at room temperature catalyzed by Pd NPs-UVM-7/PDA-n and Pd NPs-UVM-7 catalysts

\begin{tabular}{|c|c|c|c|c|c|c|}
\hline \multirow{2}{*}{$\begin{array}{l}\text { Substrate } \\
\text { Catalyst (n) }\end{array}$} & \multicolumn{5}{|c|}{ 4-Nitrophenolate 1} & \multirow[b]{2}{*}{ Pd NPs-UVM-7 } \\
\hline & 1 & 2 & 3 & 4 & 5 & \\
\hline$t_{1 / 2} / s$ & 170 & 375 & 270 & 1250 & 375 & 500 \\
\hline $\mathrm{TOF}_{1 / 2} / \mathrm{h}^{-1}$ & 8470 & 3840 & 5330 & 1152 & 3840 & 2280 \\
\hline
\end{tabular}

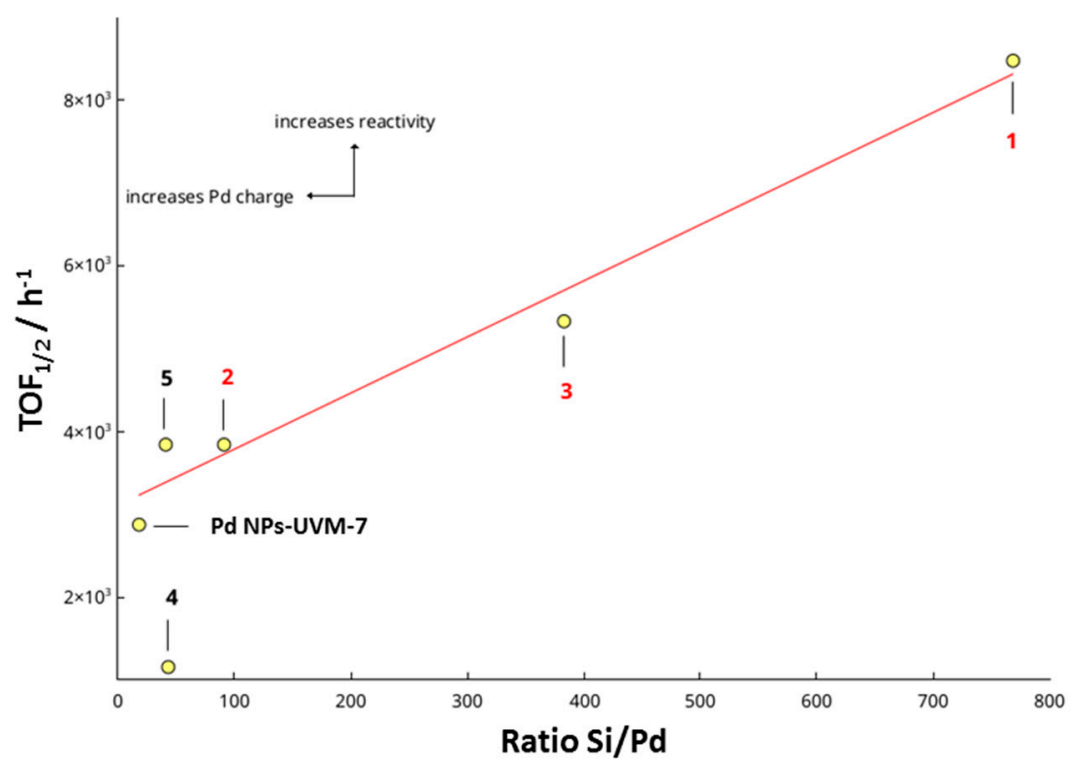

Figure 8. Correlation diagram between $\mathrm{TOF}_{1 / 2}$ and the $\mathrm{Si} / \mathrm{Pd}$ ratio. Bold red labels correspond to silica PDA covered materials Pd NPs-UVM-7/PDA-n prepared in separate steps $(\mathbf{n}=\mathbf{1}, \mathbf{2}, \mathbf{3})$; black bold labels correspond to one-pot produced materials $(n=4,5)$. Pd NPs-UVM-7 is the silica nude material taken as the reference. 
The activity of the materials was compared with that described in the literature. Although the activity of a large number of catalysts has been tested against the reduction of 4-nitrophenolate with borohydride, the problem of comparison is not trivial, due to the different criteria followed by different researchers, and the incompleteness of the data, especially those referred to as mass of Pd introduced in the reactor. In the literature, catalyst activity has been compared directly by means of the value of apparent rate constants $(\mathrm{k})$, a widely used criterion, or from TOF values. The use of $k$ is completely inappropriate, because it is an apparent constant and therefore depends on the concentration of borohydride. The TOFs, in addition, present the problem of being dependent on reaction time, so the value of the conversion and the time needed to achieve it must also be reported.

Table 4 shows the $\mathrm{TOF}_{1 / 2}$ values for about 20 catalysts worked out from Equation (2), along with the information needed for their calculation (gathered from the various papers cited). Since the half-life decreases with increasing borohydride concentration, we also report a corrected turn-over frequency consisting of dividing $\mathrm{TOF}_{1 / 2}$ by the borohydride concentration: $\mathrm{TOF}_{1 / 2}^{\prime}=\mathrm{TOF}_{1 / 2} /\left[\mathrm{BH}_{4}{ }^{-}\right]$. Based on the $\mathrm{TOF}_{1 / 2}$ value alone, the table indicates that Pd NPs-UVM-7/PDA- 1 is quite active, but not the best, as it ranks sixth. However, a more detailed analysis suggests that the highest observed TOFs were calculated from experiments driven in highly concentrated borohydride media. When the $\mathrm{TOF}_{1 / 2}$ value is separated from the co-reactant concentration influence (i.e., $\mathrm{TOF}^{\prime}{ }_{1 / 2}$ ), the description of the activity varies dramatically. Thus, material Pd NPs-UVM-7/PDA-1 exhibits the highest intrinsic reactivity appearing now at the top of the table. It is worth noting that Pd NPs supported on graphene oxide that had the highest $\operatorname{TOF}_{1 / 2}\left(34625 \mathrm{~h}^{-1}\right)$ exhibit, however, a discrete $\operatorname{TOF}_{1 / 2}^{\prime}\left(6.92 \mathrm{~h}^{-1} \mathrm{M}^{-1}\right)$, suggesting that its intrinsic reactivity is far from that calculated on TOF values alone. These data allow concluding that the multi-step synthesis of Pd NPs on a PDA silica-core support is a promising route that leads to high-performance catalysts. Preliminary characterization data on the used catalysts show that no significant leaching or aggregation of the Pd NPs occurs. In fact, the STEM images of the PDA-1 reused catalyst (Figure S6) preserve the previously mentioned domains heterogeneity with Pd Nps-rich zones. More work is needed in order to known in a conclusive way the long-term reusability of the catalysts.

Table 4. $\mathrm{TOF}_{1 / 2}$ for diverse supported/stabilized Pd NPs systems

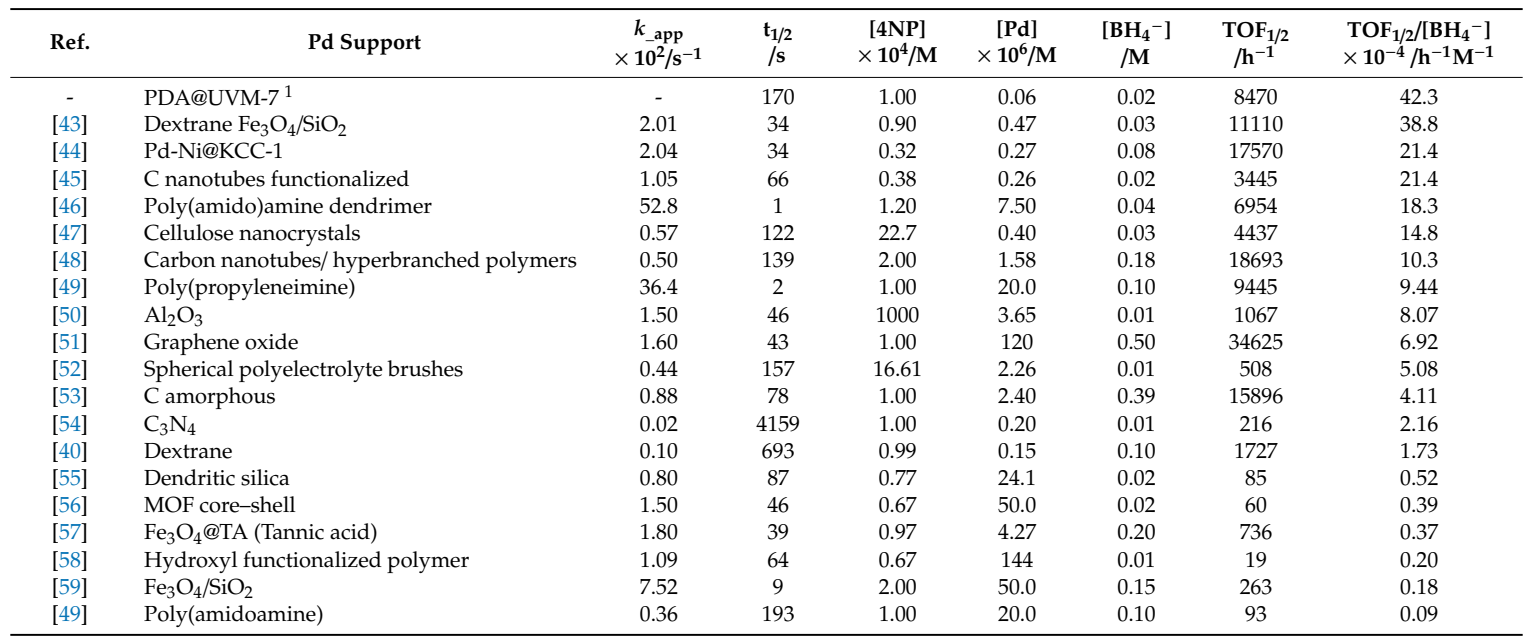

${ }^{1}$ This work: Pd NPs-UVM-7/PDA-1 catalyst.

\section{Materials and Methods}

\subsection{Reagents and Materials}

The mesoporous silica UVM-7 was synthesized according to the procedure described in the literature [31]. Commercially available ethanol $(\mathrm{EtOH}), \mathrm{HCl}, \mathrm{KCl}$, dopamine hydrochloride (DA), $\mathrm{PdCl}_{2}$, nitrophenol, 4-substituted nitrobenzene compounds, $\mathrm{NEt}_{4} \mathrm{BH}_{4}$, and $\mathrm{NaBH}_{4}$ were supplied by Aldrich. HPLC grade $\mathrm{CH}_{3} \mathrm{CN}$ (from Baker). All reagents were used without further purification. 


\subsection{Catalyst Synthesis: Coating the UVM-7 with Polidopamine (UVM-7/PDA)}

$500 \mathrm{mg}$ of silica UVM-7 were dispersed in $50 \mathrm{ml}$ of the tampon Tris- $\mathrm{HCl}$ solution $(\mathrm{pH}=8.5)$ and the suspension was sonicated during $35^{\prime}$ after that $250 \mathrm{mg}$ of DA was added and again the suspension was sonicated during other $35^{\prime}$ and kept under stirring for $24 \mathrm{~h}$. The dark brown solid obtained was washed by centrifugation at $12000 \mathrm{rpm}$ first with $\mathrm{H}_{2} \mathrm{O}$ and finally with $\mathrm{EtOH} / \mathrm{H}_{2} \mathrm{O}$ (1:1) until to get a colorless wash water. The solid was air dried $(637 \mathrm{mg})$.

\subsection{Catalyst Synthesis: Immobilization of Pd NPs on UVM-7/PDA}

Five catalysts have been prepared and labeled as Pd NPs-UVM-7/PDA-n ( $\mathbf{n}=\mathbf{1}$ to $\mathbf{5})$. The synthesis procedures are detailed below.

Pd NPs-UVM-7/PDA-1: $642 \mathrm{mg}$ of UVM-7/PDA were dispersed in $50 \mathrm{ml}$ of $\mathrm{H}_{2} \mathrm{O}$ and a solution of $\mathrm{H}_{2}\left[\mathrm{PdCl}_{4}\right]$ obtained by reaction of $37 \mathrm{mg}$ of $\mathrm{PdCl}_{2}$ with $2.1 \mathrm{ml}$ of $\mathrm{HCl} 0.2 \mathrm{M}$ was added drop by drop and the suspension was stirred for $24 \mathrm{~h}$. The solid isolated by centrifugation was dispersed in $50 \mathrm{~mL}$ of $\mathrm{H}_{2} \mathrm{O}$ and a freshly solution of $\mathrm{NaBH}_{4} 0.07 \mathrm{M}$ was added slowly. The dispersion was sonicated during $1 \mathrm{~h}$ and kept under stirring for $24 \mathrm{~h}$. The solid was washed by centrifugation at $12000 \mathrm{rpm}$ first with $\mathrm{H}_{2} \mathrm{O}$ and finally with $\mathrm{EtOH} / \mathrm{H}_{2} \mathrm{O}(1: 1)$ and air dried $(892 \mathrm{mg})$.

Pd NPs-UVM-7/PDA-2: $637 \mathrm{mg}$ of UVM-7/PDA were dispersed in $50 \mathrm{ml}$ of $\mathrm{H}_{2} \mathrm{O}$ and a filtered solution of $\mathrm{K}_{2}[\mathrm{PdCl} 4]$ obtained by reaction of $15 \mathrm{mg}$ of $\mathrm{PdCl}_{2}$ with $20 \mathrm{mg}$ of $\mathrm{KCl}$ in $\mathrm{H}_{2} \mathrm{O}$ was slowly added. The suspension was sonicated for $1 \mathrm{~h}$ and stirred for $24 \mathrm{~h}$ and a freshly solution of $\mathrm{NaBH}_{4}$ $0.07 \mathrm{M}$ was added drop by drop. The dispersion was sonicated during $1 \mathrm{~h}$ and kept under stirring for $24 \mathrm{~h}$. The solid was washed by centrifugation at $12000 \mathrm{rpm}$ first with $\mathrm{H}_{2} \mathrm{O}$ and finally with $\mathrm{EtOH} / \mathrm{H}_{2} \mathrm{O}$ (1:1) and air dried (518 mg).

Pd NPs-UVM-7/PDA-3: $603 \mathrm{mg}$ of UVM-7/PDA were dispersed in $50 \mathrm{ml}$ of $\mathrm{H}_{2} \mathrm{O}$ and a solution of $\mathrm{H}_{2}\left[\mathrm{PdCl}_{4}\right]$ obtained by reaction of $40 \mathrm{mg}$ of $\mathrm{PdCl}_{2}$ with $2 \mathrm{~mL}$ of $\mathrm{HCl} 0.3 \mathrm{M}$ was slowly added. The suspension was stirred for $24 \mathrm{~h}$ and a freshly solution of $\mathrm{NaBH}_{4} 0.07 \mathrm{M}$ was added drop by drop after that it was sonicated during $1 \mathrm{~h}$ and kept under stirring for $24 \mathrm{~h}$. The solid was washed by centrifugation at $12000 \mathrm{rpm}$ first with $\mathrm{H}_{2} \mathrm{O}$ and finally with $\mathrm{EtOH} / \mathrm{H}_{2} \mathrm{O}$ (1:1) and air dried (786 mg).

Pd NPs-UVM-7/PDA-4: $250 \mathrm{mg}$ of DA, $500 \mathrm{mg}$ of UVM-7, and a solution of $\mathrm{H}_{2}\left[\mathrm{PdCl}_{4}\right]$ obtained by reaction of $37 \mathrm{mg}$ of $\mathrm{PdCl}_{2}$ with $2.1 \mathrm{ml}$ of $\mathrm{HCl} 0.2 \mathrm{M}$ were added to $50 \mathrm{ml}$ of the tampon Tris- $\mathrm{HCl}$ solution $\mathrm{pH}=8.5$ ). The suspension was stirred for $24 \mathrm{~h}$. The solid isolated by centrifugation was dispersed in $50 \mathrm{ml}$ of $\mathrm{H}_{2} \mathrm{O}$ and a freshly solution of $\mathrm{NaBH}_{4} 0.07 \mathrm{M}$ was added slowly. The dispersion was sonicated during $1 \mathrm{~h}$ and kept under stirring for $24 \mathrm{~h}$. The solid was washed by centrifugation at $12000 \mathrm{rpm}$ first with $\mathrm{H}_{2} \mathrm{O}$ and finally with $\mathrm{EtOH} / \mathrm{H}_{2} \mathrm{O}(1: 1)$ and air dried $(879 \mathrm{mg})$.

Pd NPs-UVM-7/PDA-5: A filtered solution of $\mathrm{K}_{2}\left[\mathrm{PdCl}_{4}\right]$ obtained by reaction of $37 \mathrm{mg}$ of $\mathrm{PdCl}_{2}$ with $20 \mathrm{mg}$ of $\mathrm{KCl}$ in $\mathrm{H}_{2} \mathrm{O}$ was slowly added to a suspension of $254 \mathrm{mg}$ of DA and $503 \mathrm{mg}$ of UVM-7 in $50 \mathrm{ml}$ of the tampon Tris- $\mathrm{HCl}$ solution $\mathrm{pH}=8.5$ ). The mixture was stirred for $24 \mathrm{~h}$. The solid isolated by centrifugation was dispersed in $50 \mathrm{ml}$ of $\mathrm{H}_{2} \mathrm{O}$ and a freshly solution of $\mathrm{NaBH}_{4} 0.07 \mathrm{M}$ was added slowly. The dispersion was sonicated during $1 \mathrm{~h}$ and kept under stirring for $24 \mathrm{~h}$. The solid was washed by centrifugation at $12000 \mathrm{rpm}$ first with $\mathrm{H}_{2} \mathrm{O}$ and finally with $\mathrm{EtOH} / \mathrm{H}_{2} \mathrm{O}(1: 1)$ and air dried $(823 \mathrm{mg})$.

Pd NPs-UVM-7: For comparative purposes, we have synthesized a composite without PDA according to the preparative procedure previously described in detail [1].

\subsection{Characterization Techniques}

TGA (Thermal Gravimetric Analysis) curves were recorded with a Setaram Setsys 16/18 thermobalance (Setaram Instrumentation, Caluire-et-Cuire, France) under an air atmosphere flowing at $25 \mathrm{ml}$ per $\mathrm{min}$ (heating rate of $5^{\circ} \mathrm{C} / \mathrm{min}$ ). The Pd contents were determined by energy dispersive X-ray spectroscopy (EDX) analysis using a scanning electron microscope (Philips - SEM-XL 30 (Eindhoven, The Netherlands). FTIR (Fourier-transform infrared spectroscopy) spectra were collected on a Nicolet 4700 spectrometer (Thermo Fisher Scientific, Waltham, MA, USA). The spectra were registered (using 
self-disks of $1 \%$ sample in $\mathrm{KBr}$ ) at room-temperature and the spectrometer was continuously purged with dry air. For electron microscopy analyses, the samples were dispersed in ethanol and placed onto a carbon coated copper microgrid and left to dry before observation. The TEM (transmission electron microscopy) and HRTEM (high resolution transmission electron microscopy) microstructural characterizations were carried out using a JEOL JEM-1010 instrument operating at $100 \mathrm{kV}$ and equipped with a CCD camera and a Tecnai G2 F20(FI) instrument, respectively. STEM-HAADF (scanning transmission electron microscopy-high-angle annular dark-field) images were acquired on a JEOL-2100F microscope operated at $200 \mathrm{kV}$ (JEOL Ltd., Tokio, Japan). The particle size analysis has been performed by using the Image $1.52 \mathrm{q}$ software [60]. Powder X-ray diffraction (XRD) was carried out using a Bruker D8 Advance diffractometer (Bruker AXS GmbH, Karlsruhe, Germany) with monochromatic Cu $\mathrm{K} \alpha$ source operated at $40 \mathrm{kV}$ and $40 \mathrm{~mA}$. Patterns were collected in steps of $0.02^{\circ}(2 \theta)$ over the angular range $1-10.0^{\circ}(2 \theta)$, with an acquisition time of $25 \mathrm{~s}$ per step. Additionally, XRD patterns were recorded over a wider angular range, $10-80^{\circ}(2 \theta)$ to determine the presence of segregated crystalline phases. Surface area values were calculated from nitrogen adsorption-desorption isotherms were recorded in an automated Micromeritics ASAP2020 instrument (Micromeritics Instrument Corp., Norcross, GA, USA). Prior to the adsorption measurements, the samples were out-gassed in situ in vacuum $\left(10^{-6}\right.$ Torr $)$ at $120^{\circ} \mathrm{C}$ for 15 hours to remove adsorbed gases. Surface areas were estimated according to the Brunauer-Emmett-Teller (BET) model [61], and pore size dimensions and pore volumes were calculated by using the Barrett-Joyner-Halenda (BJH) method [62] from the absorption branch of the isotherms. FTIR spectra of UVM-7/PDA support and the precatalysts were characterized using an Agilent Cary 630 FTIR spectrophotometer (Agilent Technologies, Santa Clara, CA, USA).

\subsection{Kinetic Study}

The kinetic study was carried out using an Agilent 8453 UV-vis diode-array (DA) spectrophotometer by recording the absorbance between 225 to $600 \mathrm{~nm}$ at regular time intervals at $25^{\circ} \mathrm{C}$. In a $1 \mathrm{~cm}$ path quartz cell, it were introduced a solution of 4-nitrophenol $\left(10^{-4} \mathrm{M}\right.$, solvent $\left.\mathrm{H}_{2} \mathrm{O}, 1.5 \mathrm{ml}\right)$ containing the catalyst $\left(0.125 \%\right.$ in mole respect to nitroarene, solvent $\left.\mathrm{H}_{2} \mathrm{O}\right)$ and a freshly prepared solution of $\left(\mathrm{NEt}_{4}\right) \mathrm{BH}_{4}\left(0.04 \mathrm{M}\right.$, solvent $\left.\mathrm{CH}_{3} \mathrm{CN}, 1.5 \mathrm{ml}\right)$. The catalyst solution was prepared dispersing by sonication the appropriate mass of catalyst $(4-5 \mathrm{mg})$ in $5 \mathrm{ml}$ of water.

The absorbance measurement procedure was as follows: The spectrophotometer was zeroed against a solution of acetonitrile:water $(1: 1 \mathrm{v} / \mathrm{v})$, thereafter the spectrum of a catalyst dispersion having the same concentration than the sample was recorded, and finally, the solution of 4-nitrophenol (with catalyst) and borohydride were mixed and the spectra of the reaction mixture monitored at regular time intervals. The reaction mixture was stirred magnetically to prevent catalyst deposition, and hydrogen bubbles fixing on the cell walls. The absorbance spectra were corrected by subtracting the previously recorded catalyst spectrum.

\section{Conclusions}

We have synthesized a highly efficient catalyst that has been tested for the 'model reaction' of hydrogenation of 4-nitrophenol using $\left(\mathrm{NEt}_{4}\right) \mathrm{BH}_{4}$ as the hydrogenating agent. The best catalyst is a composite based on isolated Pd NPs decorating the PDA/UVM-7 surface. Regardless the support nature, the TOF values achieved are among the best described in the bibliography. These excellent results open up the possibility of using these catalysts for other related reactions of industrial interest such as the reduction of nitroarenes.

Supplementary Materials: The following are available online at http://www.mdpi.com/2073-4344/10/4/449/s1; Figure S1: TGA curves of the catalysts; Figure S2: Selected FTIR spectrum; Figure S3: high-angle XRD patterns; Figure S4: low-angle XRD patterns; Figure S5: Graphic explanation of the meaning of the induction, (tind) and half-time (t1/2) times cited in the text; Figure S6: HAADF-STEM images of the Pd NPs-UVM-7/PDA-1 used catalyst.

Author Contributions: Catalysts synthesis, M.R. and J.E.H.; Catalysts characterization, J.E.H., J.V.R.-L., M.D.M., and P.A.; Catalytic study, M.R., M.Á.Ú., and F.P.-P.; Conceptualization, P.A., M.Á.Ú., and F.P.-P.; Methodology, 
P.A., M.Á.Ú., and F.P.-P.; Writing—original draft preparation, writing—review and editing and supervision, P.A., M.Á.Ú., and F.P.-P. All authors have read and agreed to the published version of the manuscript.

Funding: This research was funded by the Ministerio de Ciencia, Innovación y Universidades and FEDER of Spain, grant number RTI2018-100910-B-C44.

Acknowledgments: We appreciate the technical support of the SCSIE of the Universitat de Valencia and the Electron Microscopy Service of the Universidad Politécnica de Valencia.

Conflicts of Interest: The authors declare no conflict of interest.

\section{References}

1. Albiñana, P.A.; El Haskouri, J.; Marcos, M.D.; Estevan, F.; Amorós, P.; Úbeda, M.Á.; Pérez-Pla, F. A new efficient, highly dispersed, Pd nanoparticulate silica supported catalyst synthesized from an organometallic precursor. Study of the homogeneous vs. heterogeneous activity in the Suzuki-Miyaura reaction. J. Catal. 2018, 367, 283-295. [CrossRef]

2. Zhang, M.; Liu, G.; Sun, X.; Jiang, Y.; Zhang, X. General promoting effect of polydopamine on supported noble metal catalysts. J. Mater. Chem. A 2017, 5, 20789-20796. [CrossRef]

3. Liu, Y.; Li, G.; Qin, R.; Chen, D. Surface-Engineered Polidopamine Particles as an Efficient Support for Catalytic Applications. Langmuir 2016, 32, 13675-13686.

4. Lee, H.; Dellatore, S.M.; Miller, W.M.; Messersmith, P.B. Mussel-Inspired Surface Chemistry for Multifunctional Coatings. Science 2007, 318, 426-430. [CrossRef]

5. Ryu, J.H.; Meserssmith, P.B.; Lee, H. Polidopamine Surface Chemistry: A Decade of Discovery. ACS Appl. Mater. Interfaces 2018, 10, 7523-7540.

6. Liu, Y.; Ai, K.; Lu, L. Polydopamine and Its Derivative Materials: Synthesis and Promising Applications in Energy, Environmental, and Biomedical Fields. Chem. Rev. 2014, 114, 5057-5115. [CrossRef]

7. Qu, R.; Zhang, W.; Liu, N.; Zhang, Q.; Liu, Y.; Li, X.; Wei, Y.; Feng, L. Antioil Ag3PO4 Nanoparticle/Polydopamine/Al2O3 Sandwich Structure for Complex Wastewater Treatment: Dynamic Catalysis under Natural Light. ACS Sustain. Chem. Eng. 2018, 6, 8019-8028. [CrossRef]

8. Kralj, S.; Longobardo, F.; Iglesias, D.; Bevilacqua, M.; Tavagnacco, C.; Criado, A.; Jaen, J.J.D.; Makovec, D.; Marchesan, S.; Melchionna, M.; et al. Ex-Solution Synthesis of Sub-5-nm FeOx Nanoparticles on Mesoporous Hollow N,O-Doped Carbon Nanoshells for Electrocatalytic Oxygen Reduction. ACS Appl. Nano Mater. 2019, 2, 6092-6097. [CrossRef]

9. Liu, R.; Guo, Y.; Odusote, G.; Qu, F.; Priestley, R. Core-Shell $\mathrm{Fe}_{3} \mathrm{O}_{4}$ Polidopamine Nanoparticles Serve Multipurpose as Drug Carrier, Catalyst Support and Carbon Adsorbent. ACS Appl. Mater. Interfaces. 2013, 5, 9167-9171.

10. Huang, H.; He, Z.; Lin, X.; Ruan, W.; Liu, Y.; Yang, Z. Ultradispersed platinum nanoclusters on polydopamine-functionalized carbon nanotubes as an excellent catalyst for methanol oxidation reaction. Appl. Catal. A Gen. 2015, 490, 65-70. [CrossRef]

11. Yang, Y.; Reber, A.C.; Gilliland, S.E.; Castano, C.; Gupton, B.F.; Khanna, S.N. More than just a support: Graphene as a solid-state ligand for palladium-catalyzed cross-coupling reactions. J. Catal. 2018, 360, 20-26. [CrossRef]

12. Hussain, M.A.; Yang, M.; Lee, T.J.; Kim, J.W.; Choi, B.G. High density decoration of noble metal nanoparticles on polydopamine-functionalized molybdenum disulphide. J. Colloid Interface Sci. 2015, 451, $216-220$. [CrossRef]

13. Ma, J.-X.; Yang, H.; Zhang, X.; Li, S.; Ren, R. Well-dispersed graphene-polydopamine-Pd hybrid with enhanced catalytic performance. RSC Adv. 2015, 5, 97520-97527. [CrossRef]

14. Ye, W.; Yu, J.; Zhou, Y.; Gao, D.; Wang, D.; Wang, C.; Xue, D. Green synthesis of Pt-Au dendrimer-like nanoparticles supported on polydopamine-functionalized graphene and their high performance toward 4nitrophenol reduction. Appl. Catal. B Environ. 2016, 181, 371-378. [CrossRef]

15. Ren, F.; Zhai, C.; Zhu, M.; Wang, C.; Wang, H.; Bin, D.; Guo, J.; Yang, P.; Du, Y. Facile synthesis of PtAu nanoparticles supported on polydopamine reduced and modified graphene oxide as a highly active catalyst for methanol oxidation. Electrochimica Acta 2015, 153, 175-183. [CrossRef] 
16. Zhou, J.; Duan, B.; Fang, Z.; Song, J.; Wang, C.; Messersmith, P.B.; Duan, H. Interfacial assembly of Mussel-Inspired Au@Ag@Polydopamine Core-Shell Nanoparticles for Recyclable Nanocatalyts. Adv. Mater. 2014, 26, 701-705.

17. Sadjadi, S.; Lazzara, G.; Malmir, M.; Heravi, M.M. Pd nanoparticles immobilized on the poly-dopamine decorated hallosyte nanotubes hybridized with $\mathrm{N}$-doped porous carbon monolayer: A versatile catalyst for promoting Pd catalysed reactions. J. Catal. 2018, 366, 245-257.

18. Movahed, S.K.; Lehi, N.F.; Dabiri, M. Palladium nanoparticles supported on core-shell and York-shell $\mathrm{Fe}_{3} \mathrm{O}_{4} @$ nitrogen doped carbon cubes as highly efficient, magnetically separable catalyst for the reduction of nitroarenes and the oxidation of alcohols. J. Catal. 2018, 364, 69-79.

19. Kadam, H.; Tilve, S.G. Advancement in methodologies for reduction of nitroarenes. RSC Adv. 2015, 5, 83391-83407. [CrossRef]

20. Lara, P.; Philippot, K. The hydrogenation of nitrosoarenes mediated by platinum nanoparticles: An overview. Catal. Sci. Technol. 2014, 4, 2445-2465.

21. Corma, A. Chemoselective Hydrogenation of Nitro Compounds with Supported Gold Catalysts. Science 2006, 313, 332-334. [CrossRef] [PubMed]

22. Formenti, D.; Ferretti, F.; Scharnagl, F.K.; Beller, M. Reduction of Nitro Compounds Using 3d-Non-Noble Metal Catalysts. Chem. Rev. 2018, 119, 2611-2680. [CrossRef] [PubMed]

23. Doherty, S.; Knight, J.G.; Backhouse, T.; Bradfors, A.; Saunders, F.; Bourne, R.A.; Chamberlain, T.W.; Stones, R.; Clayton, A.; Lovelock, K. Hightly efficient aqueous phase reduction of nitroarenes catalysed by phosphine-decorated polymer immobilized ionic liquid stabilized PdNPs. Catal. Sci. Technol. 2018, 8, 1454-1467. [CrossRef]

24. Doherty, S.; Knight, J.G.; Backhouse, T.; Summers, R.J.; Abood, E.; Simpson, W.; Paget, W.; Bourne, R.A.; Chamberlain, T.W.; Stones, R.; et al. Highly Selective and Solvent-Dependent Reduction of Nitrobenzene to N-Phenylhydroxylamine, Azoxybenzene, and Aniline Catalyzed by Phosphino-Modified Polymer Immobilized Ionic Liquid-Stabilized AuNPs. ACS Catal. 2019, 9, 4777-4791. [CrossRef]

25. Orlandi, M.; Brenna, D.; Harms, R.; Jost, S.; Benaglia, M. Recent Developments in the Reduction of Aromatic and Aliphatic Nitro Compounds to Amines. Org. Process. Res. Dev. 2016, 22, 430-445. [CrossRef]

26. Wunder, S.; Lu, Y.; Albrecht, M.; Ballauff, M. Catalytic Activity of Faceted Gold Nanoparticles Studied by a Model Reaction: Evidence for Substrate-Induced Surface Restructuring. ACS Catal. 2011, 1, 908-916. [CrossRef]

27. Zhao, P.; Feng, X.; Huang, D.; Yang, G.; Astruc, D. Basic concepts and recent advances in nitrophenol reduction by gold- and other transition metal nanoparticles. Co-ord. Chem. Rev. 2015, 287, 114-136. [CrossRef]

28. Aditya, T.; Pal, A.; Pal, T. Nitroarene reduction: A trusted model reaction to test nanoparticle catalysts. Chem. Commun. 2015, 51, 9410-9431. [CrossRef]

29. Gu, S.; Wunder, S.; Lu, Y.; Ballauff, M. Kinetic Analysis of the Catalytic Reduction of 4-Nitrophenosl by Metallic Nanoparticles. J. Phys. Chem.C. 2014, 118, 18618-18625. [CrossRef]

30. El Haskouri, J.; Ortiz de Zárate, D.; Guillem, C.; Latorre, J.; Caldés, M.; Beltrán, A.; Beltrán, D.; Descalzo, A.B.; Rodríguez-López, G.; Martínez-Máñez, R.; et al. Silica-based powders and monolits with bimodal pore systems. Chem.Comm. 2002, 330-331. [CrossRef]

31. El Haskouri, J.; Morales, J.M.; De Zárate, D.O.; Fernández, L.; Latorre, J.; Guillem, C.; Beltrán, A.; Beltrán, D.; Amorós, P. Nanoparticulated Silicas with Bimodal Porosity: Chemical Control of the Pore Sizes. Inorg. Chem. 2008, 47, 8267-8277. [CrossRef] [PubMed]

32. Huerta, L.; Guillem, C.; Latorre, J.; Beltrán, A.; Martínez-Máñez, R.; Marcos, M.D.; Beltran, D.; Amorós, P. Bases for the synthesis of nanoparticulated silicas with bimodal hierarchical porosity. Solid State Sci. 2006, 8 , 940-951. [CrossRef]

33. Pérez-Cabero, M.; Hungria, A.B.; Morales, J.M.; Tortajada, M.; Ramón, D.; Moragues, A.; El Haskouri, J.; Beltrán, A.; Beltran, D.; Amorós, P.; et al. Interconnected mesopores and high accessibility in UVM-7-like silicas. J. Nanoparticle Res. 2012, 14, 14. [CrossRef]

34. Luo, H.; Gu, C.; Zheng, W.; Dai, F.; Wang, X. Facile synthesis of novel size-controlled antibacterial hybrid spheres using silver nanoparticles loaded with poly-dopamine spheres. RSC Adv. 2015, 5, 13470-13477. [CrossRef]

35. Cheng, W.; Fan, F.; Zhang, Y.; Pei, Z.; Wang, W.; Pei, Y. A Facile Approach for Fabrication of Core-Shell Magnetic Molecularly Imprinted Nanospheres towards Hypericin. Polymers 2017, 9, 135. [CrossRef] 
36. Kresge, C.T.; Leonowicz, M.E.; Roth, W.J.; Vartuli, J.; Beck, J.S.; Kresge, M.E.L.C.T. Ordered mesoporous molecular sieves synthesized by a liquid-crystal template mechanism. Nature 1992, 359, 710-712. [CrossRef]

37. Habber, F.Z. Gradual Electrolytic Reduction of Nitrobenzane with Limited Cathode Potential. Electrochem. Angew. Phys. Chem. 1898, 22, 506-514.

38. Corma, A.; Concepción, P.; Serna, P. Different Reaction Pathway for the Reduction of Aromatic Nitro Compounds on Gol Catalysts. Angew. Chem. Int. Ed. 2007, 46, 7266-7269. [CrossRef]

39. Larm, N.E.; Bhawawet, N.; Thon, J.A.; Baker, G.A. Best practices for reporting nanocatalytic performance: Lessons learned from nitroarene reduction as a model reaction. New J. Chem. 2019, 43, 17932-17936. [CrossRef]

40. Lara, L.R.S.; Zottis, A.D.; Elias, W.C.; Faggion, D.; De Campos, C.E.M.; Acuña, J.J.S.; Domingos, J. The catalytic evaluation of in situ grown Pd nanoparticles on the surface of $\mathrm{Fe}_{3} \mathrm{O}_{4} @$ dextran particles in the p-nitrophenol reduction reaction. RSC Adv. 2015, 5, 8289-8296. [CrossRef]

41. Batt, L.; Hague, D.N.; Margerison, D.; Shooter, D.; Wayne, R.P. The Practice of Kinetics. In Comprehensive Chemical Kinetics; Elsevier: Amsterdam, The Netherlands, 1969; Volume 1, p. 343.

42. Menumerov, E.; Hughes, R.A.; Neretina, S. Catalytic Reduction of 4-Nitrophenol: A Quantitative Assessment of the Role of Dissolved Oxygen in Determining the Induction Time. Nano Lett. 2016, 16, 7791-7797. [CrossRef] [PubMed]

43. An, M.; Cui, J.; Wang, L. Magnetic Recyclable Nanocomposite Catalysts with Good Dispersibility and High Catalytic Activity. J. Phys. Chem. C 2014, 118, 3062-3068. [CrossRef]

44. Dong, Z.; Le, X.; Dong, C.; Zhang, W.; Li, X.; Ma, J. Ni@Pd core-shell nanoparticles modified fibrous silica nanospheres as highly efficient and recoverable catalyst for reduction of 4-nitrophenol and hydrodechlorination of 4-chlorophenol. Appl. Catal. B Environ. 2015, 162, 372-380. [CrossRef]

45. Gu, X.; Qi, W.; Xu, X.; Sun, Z.; Zhang, L.; Liu, W.; Pan, X.; Su, D. Covalently functionalized carbon nanotube supported Pd nanoparticles for catalytic reduction of 4-nitrophenol. Nanoscale 2014, 6, 6609-6616. [CrossRef] [PubMed]

46. Johnson, J.A.; Makis, J.J.; Marvin, K.A.; Rodenbusch, S.E.; Stevenson, K.J. Size-Dependent Hydrogenation of p-Nitrophenol with Pd Nanoparticles Synthesized with Poly(amido)amine Dendrimer Templates. J. Phys. Chem. C 2013, 117, 22644-22651. [CrossRef]

47. Wu, X.; Lu, C.; Zhang, W.; Yuan, G.; Xiong, R.; Zhang, X. A novel reagentless approach for synthesizing cellulose nanocrystal-supported palladium nanoparticles with enhanced catalytic performance. J. Mater. Chem. A 2013, 1, 8645. [CrossRef]

48. Li, H.; Han, L.; Cooper-White, J.; Kim, I. Palladium nanoparticles decorated carbon nanotubes: Facile synthesis and their applications as highly efficient catalysts for the reduction of 4-nitrophenol. Green Chem. 2012, 14, 586. [CrossRef]

49. Esumi, K.; Isono, R.; Yoshimura, T. Preparation of PAMAM- and PPI-Metal (Silver, Platinum, and Palladium) Nanocomposites and Their Catalytic Activities for Reduction of 4-Nitrophenol. Langmuir 2004, 20, 237-243. [CrossRef]

50. Arora, S.; Kapoor, P.; Singla, M.L. Catalytic studies of palladium nanoparticles immobilized on alumina synthesized by a simple physical precipitation method. React. Kinet. Mech. Catal. 2010, 99, 157-165. [CrossRef]

51. Dong, W.; Cheng, S.; Feng, C.; Shang, N.; Gao, S.; Wang, C. Fabrication of highly dispersed Pd nanoparticles supported on reduced graphene oxide for catalytic reduction of 4-nitrophenol. Catal. Commun. 2017, 90, 70-74. [CrossRef]

52. Mei, Y.; Lu, Y.; Polzer, F.; Ballauff, M.; Drechsler, M. Catalytic Activity of Palladium Nanoparticles Encapsulated in Spherical Polyelectrolyte Brushes and Core-Shell Microgels. Chem. Mater. 2007, 19, 1062-1069. [CrossRef]

53. Fang, Y.; Wang, E. Simple and direct synthesis of oxygenous carbon supported palladium nanoparticles with high catalytic activity. Nanoscale 2013, 5, 1843. [CrossRef] [PubMed]

54. Fageria, P.; Uppala, S.; Nazir, R.; Gangopadhyay, S.; Chang, C.-H.; Basu, M.; Pande, S. Synthesis of Monometallic ( $\mathrm{Au}$ and $\mathrm{Pd}$ ) and Bimetallic (AuPd) Nanoparticles Using Carbon Nitride (C3N4) Quantum Dots via the Photochemical Route for Nitrophenol Reduction. Langmuir 2016, 32, 10054-10064. [CrossRef] [PubMed] 
55. Le, X.; Dong, Z.; Li, X.; Zhang, W.; Le, M.; Ma, J. Fibrous nano-silica supported palladium nanoparticles: An efficient catalyst for the reduction of 4-nitrophenol and hydrodechlorination of 4-chlorophenol under mild conditions. Catal. Commun. 2015, 59, 21-25. [CrossRef]

56. Wang, C.; Zhang, H.; Feng, C.; Gao, S.; Shang, N.; Wang, Z. Multifunctional Pd@MOF core-shell nanocomposite as highly active catalyst for p-nitrophenol reduction. Catal. Commun. 2015, 72, $29-32$. [CrossRef]

57. Veisi, H.; Pirhayati, M.; Kakanejadifard, A.; Mohammadi, P.; Abdi, M.R.; Gholami, J.; Hemmati, S. In Situ Green Synthesis of Pd Nanoparticles on Tannic Acid-Modified Magnetite Nanoparticles as a Green Reductant and Stabilizer Agent: Its Application as a Recyclable Nanocatalyst $\left(\mathrm{Fe}_{3} \mathrm{O}_{4} @ \mathrm{TA} / \mathrm{Pd}\right)$ for Reduction of 4-Nitrophenol and Suzuki Reactions. ChemistrySelect 2018, 3, 1820-1826. [CrossRef]

58. Qian, H.; He, Q.; Zheng, J.; Li, S.; Zhang, S. Catechol-functionalized microporous organic polymer as supported media for Pd nanoparticles and its high catalytic activity. Polymer 2014, 55, 550-555. [CrossRef]

59. Farzad, E.; Veisi, H. $\mathrm{Fe}_{3} \mathrm{O}_{4} / \mathrm{SiO}_{2}$ nanoparticles coated with polydopamine as a novel magnetite reductant and stabilizer sorbent for palladium ions: Synthetic application of $\mathrm{Fe}_{3} \mathrm{O}_{4} / \mathrm{SiO}_{2} @ \mathrm{PDA} / \mathrm{Pd}$ for reduction of 4-nitrophenol and suzuki reactions. J. Ind. Eng. Chem. 2018, 60, 114-124. [CrossRef]

60. Schneider, C.A.; Rasband, W.S.; Eliceiri, K.W. NIH Image to ImageJ: 25 years of image analysis. Nature methods 2012, 9, 671-675. [CrossRef]

61. Brunauer, S.; Emmett, P.H.; Teller, E. Adsorption of Gases in Multimolecular Layers. J. Am. Chem. Soc. 1938, 60, 309-319. [CrossRef]

62. Barrett, E.P.; Joyner, L.G.; Halenda, P.P. The Determination of Pore Volume and Area Distributions in Porous Substances. I. Computations from Nitrogen Isotherms. J. Am. Chem. Soc. 1951, 61, 373-380. [CrossRef]

(C) 2020 by the authors. Licensee MDPI, Basel, Switzerland. This article is an open access article distributed under the terms and conditions of the Creative Commons Attribution (CC BY) license (http://creativecommons.org/licenses/by/4.0/). 